\title{
Conditional survival analysis of four treatment strategies for patients with stage I non-small cell lung cancer
}

\author{
YICHENG LIANG $^{1}$, XIAOXI FAN ${ }^{1}$, YUNPENG BAI ${ }^{1}$, DEJIAN HUANG ${ }^{2}$ and CHUNLU YANG $^{1}$ \\ ${ }^{1}$ Department of Thoracic Surgery, First Hospital of China Medical University; \\ ${ }^{2}$ Department of Oncology, Shengjing Hospital of China Medical University, \\ Shenyang, Liaoning 110001, P.R. China
}

Received May 3, 2018; Accepted April 15, 2019

DOI: $10.3892 /$ ol.2019.10413

\begin{abstract}
Conditional survival (CS) is used to describe dynamic survival possibility, taking account of the change in the survival risk that occurs with longevity. The present study aimed to explore the CS of four treatment strategies for stage I non-small cell lung cancer (NSCLC), staged according to the eighth edition of the American Joint Committee on Cancer/Union for International Cancer Control NSCLC staging system. Using the Surveillance, Epidemiology and End Results Program cohort obtained between 2004-2014, the current study first extracted data for 27,116 patients with stage I NSCLC. The actuarial cancer-specific survival rates (ACSs) and conditional cancer-specific survival rates of four treatment strategies were then compared. ACS was assessed using the Kaplan-Meier method and a log-rank test. The 3-year conditional cancer-specific survival (CCS3) of patients who had already survived for $n$ years was calculated as $\mathrm{CCS} 3=\mathrm{ACS}(\mathrm{n}+3) / \mathrm{ACS}(\mathrm{n})$. Cox regression and propensity-score matching (PSM) was applied to adjust confounding factors. The 5-year ACS of patients who underwent lobectomy, sublobar resection, radiation and observation was 80.3, 72.0, 40.8 and $19.6 \%$, respectively. The 5-year CCS3 of patients who underwent lobectomy, sublobar resection, radiation and observation was 91.7, 86.4, 77.0 and 58.2\%, respectively. CCS3 increased with an increase in survival time and patients who underwent lobectomy had the highest CCS3 estimates and flattest growth, with the smallest survival gap between CCS3 and ACS. The results were similar in the PSM analysis. In conclusion, CS estimates may provide a more accurate survival prediction for patients with stage I NSCLC, and may assist with treatment decisions and surveillance strategies. In addition, the current
\end{abstract}

Correspondence to: Professor Chunlu Yang, Department of Thoracic Surgery, First Hospital of China Medical University, 155 Nanjingbei Street, Shenyang, Liaoning 110001, P.R. China E-mail: clyang@cmu.edu.cn

Key words: surveillance epidemiology and end results, conditional survival, stage I non-small cell lung cancer, treatment strategies, propensity-score matching study provided evidence that suggests lobectomy may be the optimal treatment strategy for stage I NSCLC compared with sublobar resection.

\section{Introduction}

Lung cancer is the leading cause of cancer-associated mortality worldwide; however, the prognosis of patients with early-stage non-small cell lung cancer (NSCLC) is relatively better compared with advanced NSCLC $(1,2)$. Cumulative survival following diagnosis is frequently applied to estimate prognosis, which is useful for comparisons between different groups in a study. However, this method has its limitations particularly for patients with long-term survival, as the mortality risk may change as the survival time increases (3).

Conditional survival (CS) is a concept of evaluating survival information for long-term prognosis, which takes into consideration the dynamic change in the risk of mortality as the survival period increases (4). Referring to NSCLC, certain studies have estimated CS according to a number of aspects, however, to the best of our knowledge, no study has specifically focused on CS associated with different treatment strategies of early-stage NSCLC (5-9). In the present study, the CS calculated according to actuarial cancer-specific survival (ACS) was termed the conditional cancer-specific survival (CCS) and the 3-year conditional cancer-specific survival (CCS3) was evaluated as an example. Actuarial cancer-specific survival (ACS) is designated as the cumulative survival using only cancer-associated mortalities as the outcome of interest. The CCS3 at $\mathrm{n}^{\text {th }}$ year following diagnosis was termed CCS3(n). For example, the CCS3 at the third year after diagnosis was termed CCS3(3), which means the probability for patients who have survived for $n$ years will survive an extra 3 years. The calculation method can be described as $\mathrm{CCS} 3=\operatorname{ACS}(\mathrm{n}+3) / \operatorname{ACS}(\mathrm{n})$, where $\operatorname{ACS}(\mathrm{n})$ indicates the actual cancer-specific survival rate at $n$ years.

As Shirvani et al (10) reported, the cancer-specific survival of patients with early-stage NSCLC varies depending on different treatment strategies, with patients treated by lobectomy exhibiting the highest survival rate and patients treated by observation presenting with the lowest survival rate. To accurately estimate the prognosis of early-stage NSCLC, the present study, which was based on The Surveillance, Epidemiology, 
and End Results (SEER) database, aimed to assess the ACS and CCS3 of patients with stage I NSCLC, according to the 8th edition of the American Joint Committee on Cancer/Union for International Cancer Control (AJCC/UICC) NSCLC staging system AJCC/UICC, who underwent different treatment strategies.

\section{Materials and methods}

Patient data. Data for the current study were obtained from the SEER database (11) which covers $\sim 30 \%$ of the population of the USA. A total of 270,938 cases were singularly diagnosed with primary NSCLC and recorded in the SEER database from January 2004-December 2014. The inclusion criteria of NSCLC was as previously described (12). For all patients, the following variables were collected from SEER: Ethnicity, age at diagnosis, sex, tumor size, primary site, laterality, lymph nodes, extension, metastasis, histologic type according the 3rd edition of the International Classification of Diseases for Oncology (13), grade, surgery procedures, reason for no surgery, survival months, radiation procedures, chemotherapy and SEER cause-specific death classification (11). The exclusion criteria were as follows: i) distant metastases or lymph node metastases; ii) tumor size $>4 \mathrm{~cm}$; iii) tumor invading chest wall, pericardium, phrenic nerve, mediastinum, diaphragm, heart, great vessels, recurrent laryngeal nerve, carina, trachea, esophagus and spine; iv) separate tumor nodule(s) in the same lobe or tumor nodule(s) in a different ipsilateral lobe; v) unknown survival months or incomplete clinicopathologic information, and vi) patients with stage I NSCLC who didn't received standard therapies, including lobectomy, sublobar resection, radiation or observation. Finally, these criteria yielded a sample of 27,116 patients (Fig. 1). The 8th edition of the AJCC/UICC NSCLC staging system was used to define the stage of disease (14).

Statistical analysis. ACS was assessed using the Kaplan-Meier method and a log-rank test. Furthermore, the variables with statistical significance $(\mathrm{P}<0.05)$ in univariate analysis were included in multivariate analysis to identify independent prognostic factors by Cox proportional hazard regression model.

Due to the baseline covariate differences among treatment strategies, a further exploratory analysis was performed, namely propensity-score matching (PSM), to compare both ACS and CCS3 in surgical groups and non-surgical groups for the purpose of ultimately avoiding bias introduced by other independent prognostic factors. PSM was calculated using a logistic model with independent prognostic factors following assessment by Cox proportional hazard regression model. Patients were matched 1:1 using the nearest neighbor matching method (15).

All statistical analysis was performed using $\mathrm{R}$ program (version 3.2.2; http://www.r-project.org/) or SPSS (version 23.0; IBM Corp., Armonk, NY, USA). P $<0.05$ was considered to indicate a statistically significant difference.. Categorical variables were described as counts and the difference among them were compared with Pearson's $\chi^{2}$ test.

\section{Results}

Baseline characteristics of cases. Overall, 27,116 patients were included in the present study. The baseline characteristics of

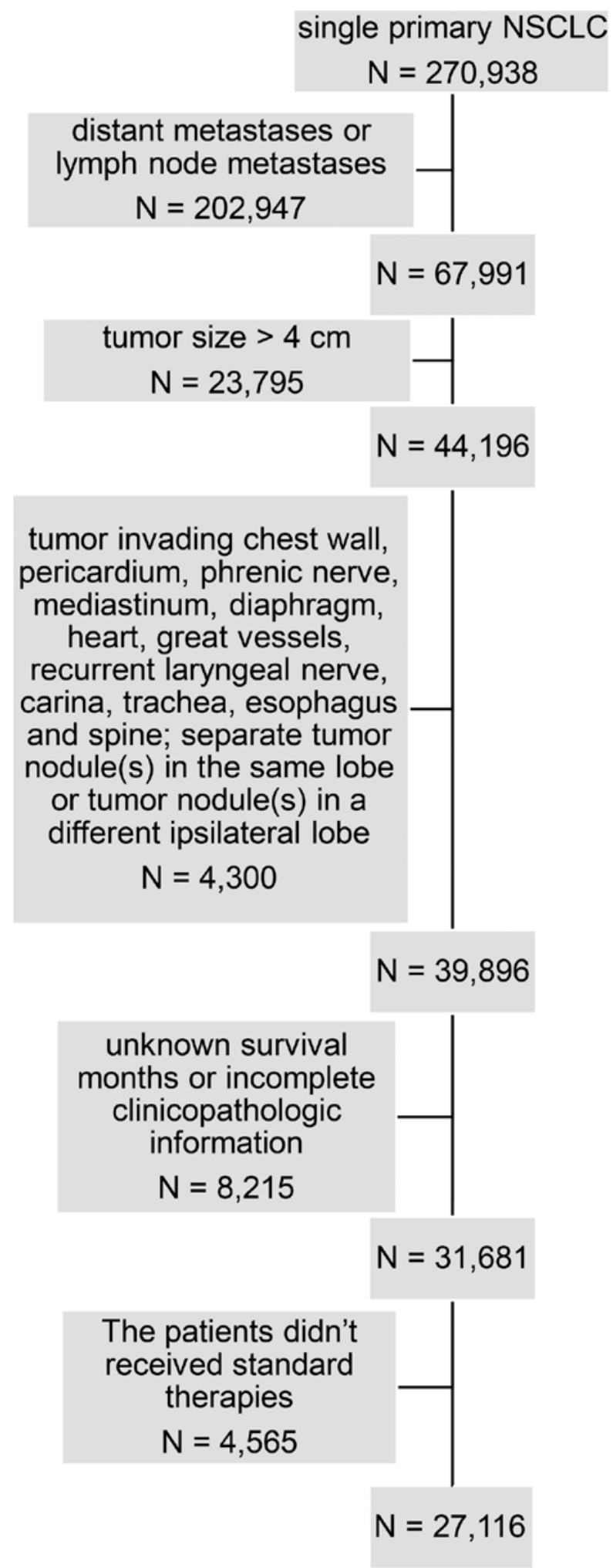

Figure 1. Flow chart for generation of the patient's cohort dataset. NSCLC, non-small cell lung cancer.

the included cases are presented in Table I. Ethnicity was classified as Caucasian or non-Caucasian as the majority of the study population were Caucasian. The median age was 70 years; therefore, the age was divided into $<70$ or $\geq 70$ years old. The histological type of the majority of NSCLC cases was adenocarcinoma or squamous cell carcinoma; therefore, 
Table I. Clinical characteristics of patients with early stage non-small cell lung cancer stratified by treatments.

\begin{tabular}{|c|c|c|c|c|c|c|}
\hline \multirow[b]{2}{*}{ Variable } & \multicolumn{3}{|c|}{ Surgical group } & \multicolumn{3}{|c|}{ Non-surgical group } \\
\hline & $\begin{array}{l}\text { Lobectomy } \\
(\mathrm{n}=18,154)\end{array}$ & $\begin{array}{l}\text { Sublobar resection } \\
\quad(\mathrm{n}=4,759)\end{array}$ & P-value & $\begin{array}{l}\text { Radiation } \\
(\mathrm{n}=2,618)\end{array}$ & $\begin{array}{c}\text { Observation } \\
(\mathrm{n}=1,585)\end{array}$ & P-value \\
\hline Age, years & & & $<0.001$ & & & 0.013 \\
\hline$<70$ & 9,963 & 2,058 & & 659 & 454 & \\
\hline$\geq 70$ & 8,191 & 2,701 & & 1,959 & 1,131 & \\
\hline Ethnicity & & & $<0.001$ & & & $<0.001$ \\
\hline Caucasian & 15,314 & 4,116 & & 2,221 & 1,266 & \\
\hline Non-Caucasian & 2,840 & 643 & & 397 & 319 & \\
\hline Sex & & & 0.433 & & & 0.050 \\
\hline Male & 8,126 & 2,100 & & 1,151 & 746 & \\
\hline Female & 10,028 & 2,659 & & 1,467 & 839 & \\
\hline $\mathrm{T}$ classification & & & $<0.001$ & & & $<0.001$ \\
\hline T1a & 1,065 & 652 & & 70 & 52 & \\
\hline $\mathrm{Tb}$ & 6,202 & 2,039 & & 856 & 411 & \\
\hline $\mathrm{Tc}$ & 5,027 & 884 & & 945 & 575 & \\
\hline T2 Cent, Visc P1 & 2,653 & 784 & & 125 & 121 & \\
\hline T2a & 3,207 & 400 & & 622 & 426 & \\
\hline Histology & & & $<0.001$ & & & $<0.001$ \\
\hline $\mathrm{AD}$ & 12,259 & 3,017 & & 1,229 & 793 & \\
\hline NSCC & 1,171 & 342 & & 288 & 218 & \\
\hline $\mathrm{SC}$ & 4,724 & 1,400 & & 1,101 & 574 & \\
\hline Grade & & & 0.119 & & & 0.246 \\
\hline I-II & 12,414 & 3,198 & & 1,364 & 855 & \\
\hline III-IV & 5,740 & 1,561 & & 1,254 & 730 & \\
\hline Laterality & & & $<0.001$ & & & 0.988 \\
\hline Left & 7,218 & 2,084 & & 1,137 & 688 & \\
\hline Right & 10,936 & 2,675 & & 1,481 & 897 & \\
\hline Sites in lung & & & 0.001 & & & 0.752 \\
\hline Upper lobe & 11,498 & 3,084 & & 1,619 & 964 & \\
\hline Middle lobe & 1,027 & 197 & & 122 & 71 & \\
\hline Lower lobe & 5,616 & 1,475 & & 857 & 534 & \\
\hline Main bronchus & 13 & 3 & & 20 & 16 & \\
\hline
\end{tabular}

Categorical variables were compared by using the Pearson's $\chi^{2}$ test. Cent, tumor involving main bronchus but not carina, atelectasis or hilum; Visc Pl, tumor involving visceral pleura; NSCC, histologic types of non-small cell lung cancer other than adenocarcinoma or squamous cell carcinoma; AD, adenocarcinoma; SC, squamous cell carcinoma.

other histologic types of NSCLC were categorized into the non-small cell cancer group.

Actuarial cancer-specific survival. The 5-year ACS of patients with stage I NSCLC was $73.0 \%$ and the hazard rate increased immediately after diagnosis, peaked at approximately the 18th month and then decreased over time (Fig. 2A and B). In terms of different treatment strategies, the 5-year ACS was highest for lobectomy $(80.3 \%)$ followed by sublobar resection (72.0\%), radiation (40.8\%) and observation (19.6\%), respectively $(\mathrm{P}<0.05$; Fig. $2 \mathrm{C})$. The hazard rate $(\mathrm{HR})$ value varies greatly with time, which indicates that the survival possibility is dynamic following diagnosis (Fig. 2D). The results of multivariate analysis revealed that age, $\mathrm{T}$ classification, sex, grade, sites in lung, histology and treatment strategies were significantly associated with prognosis $(\mathrm{P}<0.05$; Table II). The number of patients at risk in each year is demonstrated in Tables III and IV.

CCS3 and comparison with ACS. For all the patients involved in the present study, the CCS3(0) was equal to $\operatorname{ACS}(3)$, which was $80.6 \%$. As time progressed, the CCS3 demonstrated a stepwise improvement from $80.6 \%$ at CCS3(0) to $90.4 \%$ ay CCS3(5), while the ACS gradually decreased from $80.6 \%$ at $\operatorname{ACS}(3)$ to $66.0 \%$ at $\operatorname{ACS}(8)$ (Fig. 3). 
A

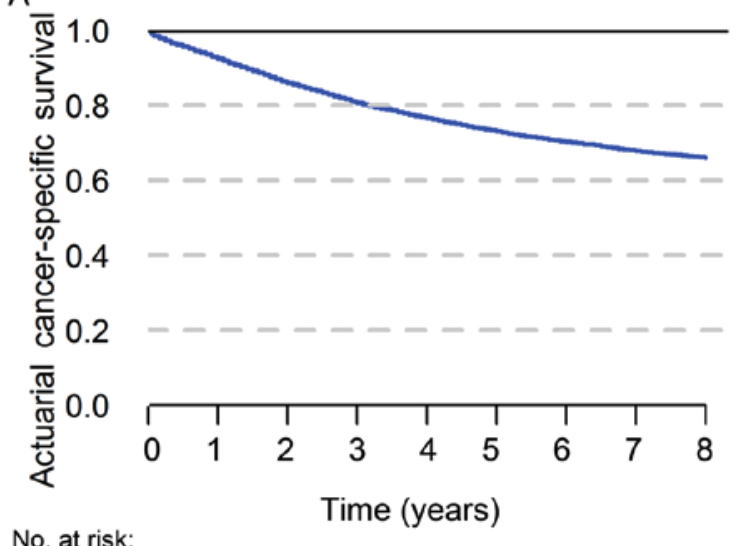

2723921000165361282698587333526236482349

C

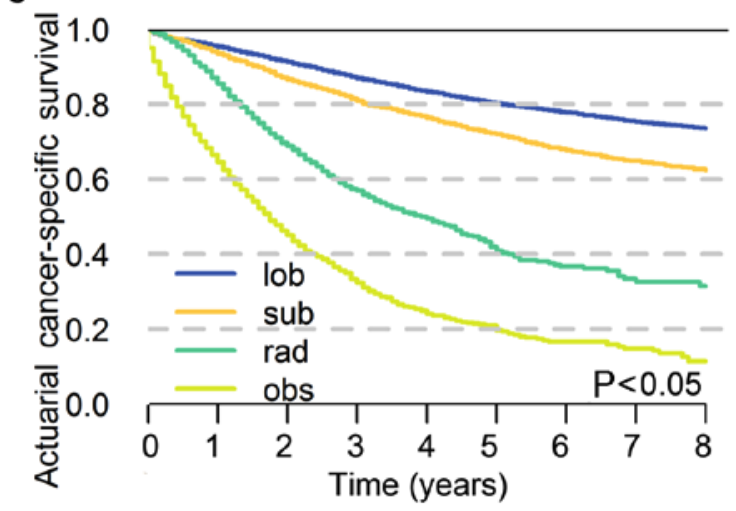

No. at risk:

lob 181541479412236985677685933434330692010

sub $4759 \quad 3700 \quad 2874 \quad 2190 \quad 1654 \quad 1170 \quad 795 \quad 500 \quad 305$

$\begin{array}{llllllllll}\mathrm{rad} & 2618 & 1715 & 1003 & 543 & 311 & 153 & 71 & 41 & 28\end{array}$

$\begin{array}{llllllllll}\text { obs } & 1585 & 791 & 423 & 237 & 125 & 77 & 51 & 31 & 11\end{array}$
B

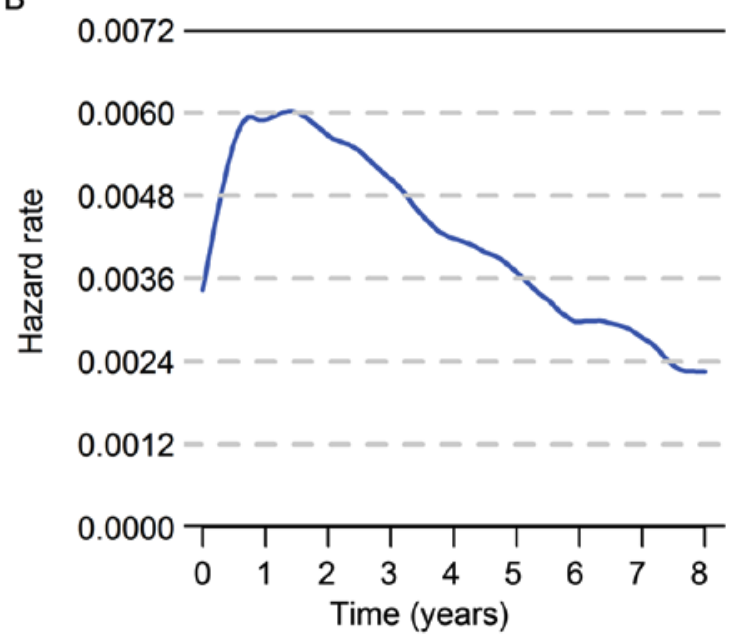

$\mathrm{D}$

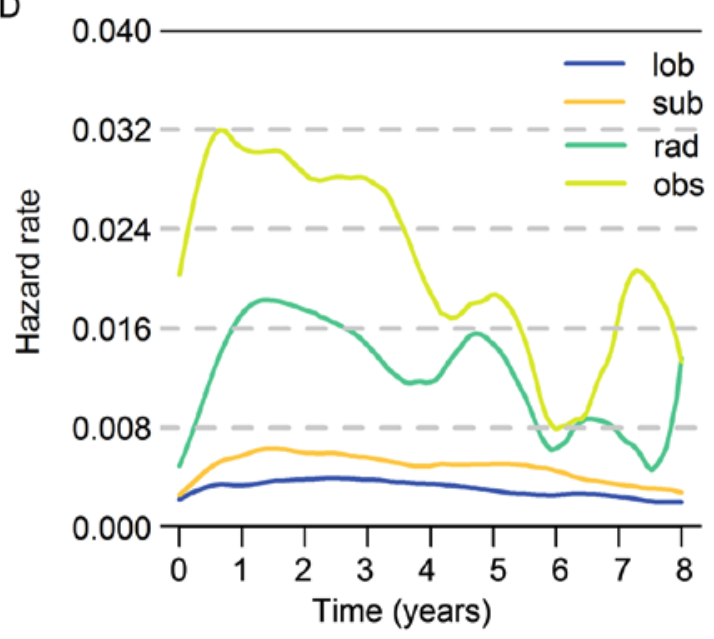

Figure 2. The actuarial cancer-specific survival and hazard rate of patients. (A) Actuarial cancer-specific survival of all patients in the cohort. (B) Hazard rate of NSCLC-associated mortality for all patients in the cohort. (C) Actuarial cancer-specific survival of patients who underwent different treatment strategies. (D) Hazard rate of NSCLC-associated mortality for patients who underwent different treatment strategies. NSCLC, non-small cell lung cancer; lob, lobectomy; sub, sublobar resection; rad, radiation; obs, observation.

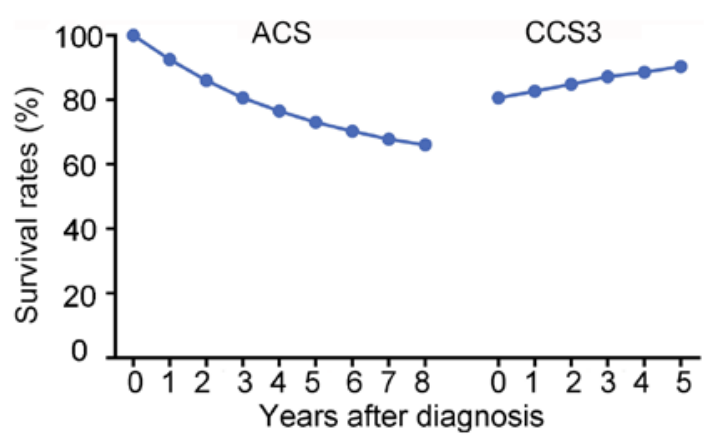

Figure 3. Comparison of ACS and CCS3 rates for all patients in the cohort. ACS, actuarial cancer-specific survival; CCS3, conditional 3-year cancer-specific survival.

In regard to the four treatment strategies, the changing trends of ACS and CCS3 were similar for all patients. The CCS3 of cases with lobectomy increased from 86.9 to $91.7 \%$, while the ACS decreased to $73.6 \%$ (8th year) from $86.9 \%$ (3rd year). In the cases with sublobar resection, the ACS gradually decreased from $80.8 \%$ at ACS(3) to $62.2 \%$ at ACS(8), while the CCS3 increased from 80.8 to $86.4 \%$. Additionally, the CCS3 of patients undergoing radiation demonstrated a gradual improvement to $77.0 \%$ and the ACS decreased from 56.9 to $31.4 \%$. Similarly, the CCS3 of patients undergoing observation increased from 32.3 to $58.2 \%$ and the ACS decreased to 11.4 from $32.3 \%$ (Fig. 4). Notably, patients who underwent non-surgical therapy demonstrated a larger survival rate gap between ACS and CCS3 compared with patients who received surgical treatment. For instance, the difference between the ACS(8) and CCS3(5) of patients who received lobectomy was $18.1 \%$, while the difference between $\operatorname{ACS}(8)$ and CCS3(5) of patients who received radiation was $45.6 \%$.

Comparison between CCS3 of treatment strategies. Among the four treatment strategies, lobectomy exhibited the highest $\mathrm{CCS} 3$ at each time point. The change in trend of $\mathrm{CCS} 3$ over time was more notable in patients who received non-surgical 
Table II. Cox Proportional Hazard Regression Model of variables.

\begin{tabular}{|c|c|c|c|c|c|c|}
\hline \multirow[b]{2}{*}{ Variable } & \multicolumn{3}{|c|}{ Univariate analysis } & \multicolumn{3}{|c|}{ Multivariate analysis } \\
\hline & P-value & HR & $95 \% \mathrm{CI}$ & P-value & $\mathrm{HR}$ & $95 \% \mathrm{CI}$ \\
\hline \multicolumn{7}{|l|}{ Age, years } \\
\hline$<70$ & - & 1.000 & - & - & 1.000 & - \\
\hline$\geq 70$ & $<0.001$ & 0.540 & $0.512-0.570$ & $<0.001$ & 0.707 & $0.669-0.748$ \\
\hline \multicolumn{7}{|l|}{ Ethnicity } \\
\hline Caucasian & - & 1.000 & - & & & \\
\hline Non-Caucasian & 0.149 & 0.947 & $0.880-1.020$ & & & \\
\hline \multicolumn{7}{|l|}{ Sex } \\
\hline Male & - & 1.000 & - & - & 1.000 & - \\
\hline Female & $<0.001$ & 0.758 & $0.720-0.799$ & $<0.001$ & 0.796 & $0.755-0.839$ \\
\hline \multicolumn{7}{|l|}{$\mathrm{T}$ classification } \\
\hline T1a & - & 1.000 & - & - & 1.000 & - \\
\hline $\mathrm{Tb}$ & $<0.001$ & 0.344 & $0.299-0.396$ & $<0.001$ & 0.445 & $0.385-0.514$ \\
\hline $\mathrm{Tc}$ & $<0.001$ & 0.454 & $0.422-0.488$ & $<0.001$ & 0.548 & $0.508-0.590$ \\
\hline T2 Cent, Visc Pl & $<0.001$ & 0.717 & $0.667-0.769$ & $<0.001$ & 0.756 & $0.704-0.812$ \\
\hline $\mathrm{T} 2 \mathrm{a}$ & $<0.001$ & 0.702 & $0.645-0.764$ & 0.025 & 0.905 & $0.83-0.988$ \\
\hline \multicolumn{7}{|l|}{ Histology } \\
\hline $\mathrm{AD}$ & - & 1.000 & - & - & 1.000 & - \\
\hline NSCC & $<0.001$ & 0.604 & $0.570-0.639$ & $<0.001$ & 0.806 & $0.759-0.856$ \\
\hline $\mathrm{SC}$ & $<0.001$ & 1.202 & $1.101-1.312$ & 0.540 & 1.028 & $0.940-1.124$ \\
\hline \multicolumn{7}{|l|}{ Grade } \\
\hline I-II & - & 1.000 & - & - & 1.000 & - \\
\hline III-IV & $<0.001$ & 1.704 & $1.617-1.795$ & $<0.001$ & 1.323 & $1.250-1.400$ \\
\hline \multicolumn{7}{|l|}{ Laterality } \\
\hline Left & - & 1.000 & - & & & \\
\hline Right & 0.236 & 1.032 & $0.979-1.088$ & & & \\
\hline \multicolumn{7}{|l|}{ Sites in lung } \\
\hline Upper lobe & - & 1.000 & - & - & 1.000 & - \\
\hline Middle lobe & $<0.001$ & 0.263 & $0.181-0.381$ & 0.021 & 0.641 & $0.440-0.935$ \\
\hline Lower lobe & $<0.001$ & 0.250 & $0.170-0.369$ & 0.059 & 0.684 & $0.462-1.014$ \\
\hline Main bronchus & $<0.001$ & 0.283 & $0.195-0.412$ & 0.042 & 0.676 & $0.463-0.986$ \\
\hline \multicolumn{7}{|l|}{ Treatment strategy } \\
\hline Observation & - & 1.000 & - & - & 1.000 & - \\
\hline Lobectomy & $<0.001$ & 0.122 & $0.113-0.132$ & $<0.001$ & 0.147 & $0.135-0.159$ \\
\hline Sublobar resection & $<0.001$ & 0.184 & $0.168-0.201$ & $<0.001$ & 0.231 & $0.210-0.253$ \\
\hline Radiation & $<0.001$ & 0.462 & $0.421-0.508$ & $<0.001$ & 0.452 & $0.412-0.497$ \\
\hline
\end{tabular}

Cent, tumor involving main bronchus but not carina, atelectasis or hilum; Visc Pl, tumor involving visceral pleura; NSCC, histologic types of non-small cell lung cancer other than adenocarcinoma or squamous cell carcinoma; AD, adenocarcinoma; SC, squamous cell carcinoma; HR, hazard ratio; CI, confidence interval.

treatment compared with those who received surgical treatment (Fig. 4). For example, the difference in CCS3 of patients treated with radiation between $\operatorname{CCS} 3(0)$ and $\operatorname{CCS} 3(5)$ was $20.1 \%$, whereas, the difference in CCS3 of patients who received lobectomy between $\operatorname{CCS} 3(0)$ and $\operatorname{CCS} 3(5)$ was only $4.8 \%$. The difference of CCS3 of patients who received sublobar resection was $5.6 \%$ between $\mathrm{CCS} 3(0)$ and $\mathrm{CCS} 3(5)$ and the group undergoing observation exhibited the most obvious improvement in CCS3, with a difference of $25.9 \%$ between $\operatorname{CCS} 3(0)$ and $\operatorname{CCS} 3(5)$.

Matched comparison of CCS3. Taking baseline covariate differences between treatment strategies into consideration, PSM was performed to establish two groups of comparisons to reveal the difference in CCS3. One comparison was between the surgical groups and the other comparison was 
Table III. Number of patients at risk in each follow-up year, prior to matching.

\begin{tabular}{|c|c|c|c|c|c|}
\hline \multirow[b]{2}{*}{ Year } & \multirow[b]{2}{*}{ Total cohort } & \multicolumn{2}{|c|}{ Surgical groups } & \multicolumn{2}{|c|}{ Non-surgical groups } \\
\hline & & Lob & Sub & Rad & Obs \\
\hline 0 & 27,239 & 18,154 & 4,759 & 2,618 & 1,585 \\
\hline 1 & 21,000 & 14,794 & 3,700 & 1,715 & 791 \\
\hline 2 & 16,536 & 12,236 & 2,874 & 1,003 & 423 \\
\hline 3 & 12,826 & 9,856 & 2,190 & 543 & 237 \\
\hline 4 & 9,858 & 7,768 & 1,654 & 311 & 125 \\
\hline 5 & 7,333 & 5,933 & 1,170 & 153 & 77 \\
\hline 6 & 5,262 & 4,343 & 795 & 71 & 51 \\
\hline 7 & 3,648 & 3,069 & 500 & 41 & 31 \\
\hline 8 & 2,349 & 2,010 & 305 & 28 & 11 \\
\hline
\end{tabular}

lob, lobectomy; sub, sublobar resection; rad, radiation; obs, observation.

Table IV. Number of patients at risk in each follow-up year, following matching.

\begin{tabular}{|c|c|c|c|c|c|c|}
\hline \multirow[b]{2}{*}{ Year } & \multicolumn{3}{|c|}{ Surgical groups } & \multicolumn{3}{|c|}{ Non-surgical groups } \\
\hline & Lob & Sub & Total cohort & $\operatorname{Rad}$ & Obs & Total cohort \\
\hline 0 & 4,724 & 4,724 & 9,448 & 1,450 & 1,450 & 2,900 \\
\hline 1 & 3,895 & 3,672 & 7,567 & 975 & 736 & 1,711 \\
\hline 2 & 3,238 & 2,849 & 6,087 & 584 & 389 & 973 \\
\hline 3 & 2,623 & 2,167 & 4,790 & 308 & 214 & 522 \\
\hline 4 & 2,082 & 1,640 & 3,722 & 174 & 112 & 286 \\
\hline 5 & 1,609 & 1,161 & 2,770 & 84 & 71 & 155 \\
\hline 6 & 1,202 & 790 & 1,992 & 67 & 49 & 116 \\
\hline 7 & 832 & 523 & 1,355 & 23 & 31 & 54 \\
\hline 8 & 604 & 303 & 907 & 9 & 11 & 20 \\
\hline
\end{tabular}

lob, lobectomy; sub, sublobar resection; rad, radiation; obs, observation.

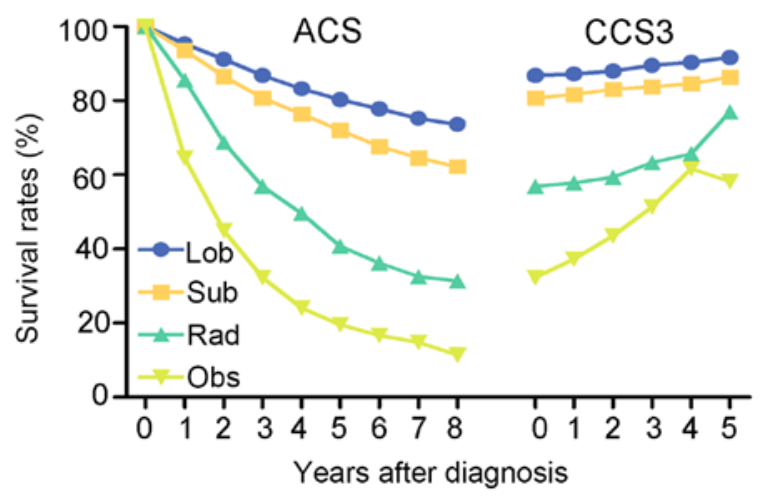

Figure 4. Comparison ACS and CCS3 rates based on four treatment strategies. ACS, actuarial cancer-specific survival; CCS3, conditional 3-year cancer-specific survival; lob, lobectomy; sub, sublobar resection; rad, radiation; obs, observation.

between the non-surgical groups. The covariates associated with prognosis were involved in the PSM. The paired cohorts were well balanced and the baseline covariate differences following PSM are presented in Table V. The lobectomy group presented with a higher ACS and CCS3 compared with the sublobar resection group, and their trends of CCS3 were almost parallel (Fig. 5A). In the non-surgical groups, the radiation group presented with a higher ACS and CCS3 compared with the observation group (Fig. 5B). The trends of the curves were similar to the unmatched ones in Fig. 4.

\section{Discussion}

Early-stage NSCLC is a malignancy with a 5-year lung cancer-specific survival rate that ranges between 20 to $80 \%$ depending of the treatment strategy (10). Traditional estimates of prognosis are typically based on different stages or pathological characteristics and are presented as cumulative survival rates calculated by follow-up data, which are obtained close to the time of diagnosis (1). However, this constant and simple information can be too limited to provide a precise estimate of prognosis, particularly when patients have survived 
Table V. Clinical characteristics of patients following propensity-score matching.

\begin{tabular}{|c|c|c|c|c|c|c|}
\hline \multirow[b]{2}{*}{ Variable } & \multicolumn{3}{|c|}{ Surgical groups } & \multicolumn{3}{|c|}{ Non-surgical groups } \\
\hline & $\begin{array}{c}\text { Lobectomy } \\
(\mathrm{n}=4,724)\end{array}$ & $\begin{array}{c}\text { Sublobar resection } \\
\qquad(\mathrm{n}=4,724)\end{array}$ & P-value & $\begin{array}{l}\text { Radiation } \\
(\mathrm{n}=1,450)\end{array}$ & $\begin{array}{l}\text { Observation } \\
(\mathrm{n}=1,450)\end{array}$ & P-value \\
\hline Age, years & & & 1.000 & & & 0.832 \\
\hline$<70$ & 2,054 & 2,054 & & 370 & 375 & \\
\hline$\geq 70$ & 2,670 & 2,670 & & 1,080 & 1,075 & \\
\hline Sex & & & 1.000 & & & 0.970 \\
\hline Male & 2,649 & 2,649 & & 786 & 785 & \\
\hline Female & 2,075 & 2,075 & & 664 & 665 & \\
\hline $\mathrm{T}$ classification & & & 1.000 & & & 0.998 \\
\hline $\mathrm{T} 1 \mathrm{a}$ & 621 & 621 & & 31 & 33 & \\
\hline $\mathrm{Tb}$ & 2,039 & 2,039 & & 408 & 404 & \\
\hline $\mathrm{Tc}$ & 884 & 884 & & 546 & 548 & \\
\hline T2 Cent, Visc P1 & 780 & 780 & & 86 & 84 & \\
\hline $\mathrm{T} 2 \mathrm{a}$ & 400 & 400 & & 379 & 381 & \\
\hline Histology & & & 1.000 & & & 0.866 \\
\hline $\mathrm{AD}$ & 2,997 & 2,997 & & 747 & 734 & \\
\hline NSCC & 1,393 & 1,393 & & 532 & 538 & \\
\hline $\mathrm{SC}$ & 334 & 334 & & 171 & 178 & \\
\hline Grade & & & 1.000 & & & 0.601 \\
\hline I-II & 3,177 & 3,177 & & 808 & 794 & \\
\hline III-IV & 1,547 & 1,547 & & 642 & 656 & \\
\hline Sites in lung & & & 1.000 & & & 0.977 \\
\hline Upper lobe & 3,066 & 3,066 & & 910 & 907 & \\
\hline Middle lobe & 194 & 194 & & 48 & 48 & \\
\hline Lower lobe & 1,462 & 1,462 & & 483 & 484 & \\
\hline Main bronchus & 2 & 2 & & 9 & 11 & \\
\hline
\end{tabular}

Cent, tumor involving main bronchus but not carina, atelectasis or hilum; Visc Pl, tumor involving visceral pleura; NSCC, histologic types of non-small cell lung cancer other than adenocarcinoma or squamous cell carcinoma; AD, adenocarcinoma; SC, squamous cell carcinoma.

for a certain time. With a long period following diagnosis, the accrued survival time may serve an important role, as the risk of recurrence and mortality are often the highest during the initial few years of follow-up after diagnosis (4-7). The present study identified that the HR increased immediately from the beginning of follow-up, then peaked within the initial 2 years, which is consistent with a study by Kim et al (9).

CS estimates, which take into consideration that the survival risk changes over time, have been proposed as a more valid method to predict long-term prognosis and estimate dynamic survival rates (16-21). The concept of CS has great practical value to provide a more accurate prediction for prognosis of early-stage NSCLC. For example, if it has been 2 years since a patient had a lobectomy, when discussing the likelihood of survival in the fifth year, only the 5-year ACS of $80.3 \%$ for patients who underwent lobectomy can be provided. This question can now be answered more appropriately with CS estimates. The current study revealed that CCS3(2) of lobectomy was $88.0 \%$, which was $7.7 \%$ higher compared with $\operatorname{ACS}(5)$ and as the survival time increased CCS3 demonstrated a stepwise improvement, while the ACS gradually decreased. This result indicates that patients may have improved odds of survival when they have survived for a certain time period. In addition, this dynamic estimate of prognosis could assist with reliving anxiety for patients concerning survival and enhance their confidence regarding their prognosis.

In the present study, the CCS3 estimates increased as time progressed and the greatest improvement was observed among patients who did not undergo treatment and presented with a poor prognosis. This finding has been conformed by other studies (21-25). The smallest increase in CCS3 was discovered among patients who underwent lobectomy. The could be explained by evidence that the ACS of patients who underwent lobectomy decreased at the slowest rate, while the ACS of patients who did not receive treatment decreased sharply. Furthermore, it was revealed that the CCS3 for the last 2 years was similar for patients who underwent observation and those who received radiation treatment. This result indicates that if patients who had no treatment survived for the initial 3 years following diagnosis, the probability that these patients will survive for another 3 years was similar to 


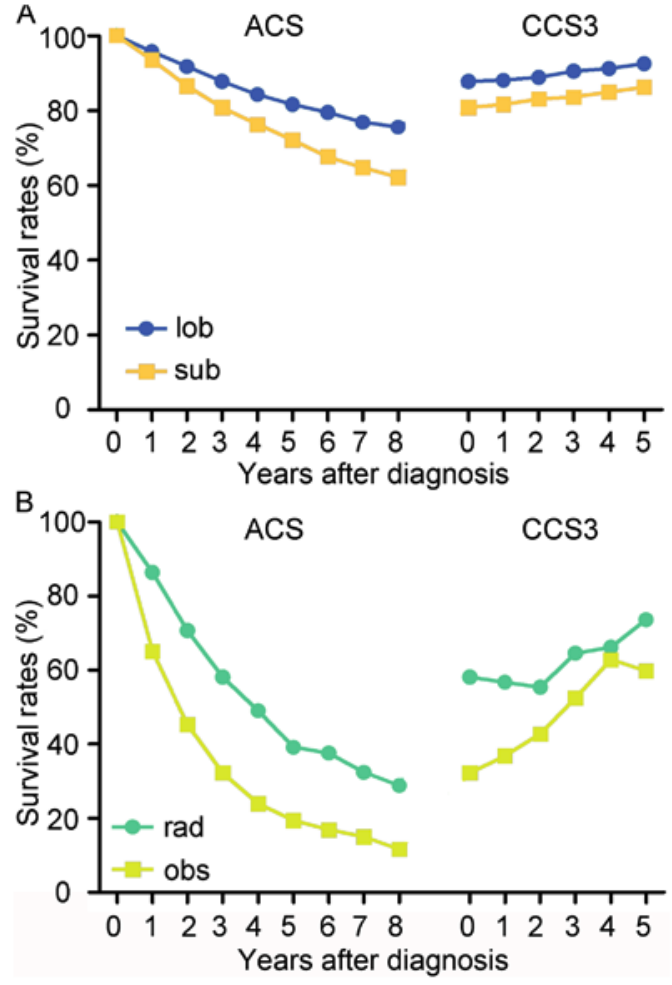

Figure 5. Comparison of ACS and CCS3 rates among surgical groups and non-surgical groups following propensity-score matching. (A) Comparison of ACS and CCS3 rates between lobectomy and sublobar resection. (B) Comparison of ACS and CCS3 rates between radiation and observation. ACS, actuarial cancer-specific survival; CCS3, conditional 3-year cancer-specific survival; lob, lobectomy; sub, sublobar resection; rad, radiation; obs, observation.

those who received radiation. A natural selection effect on the initial population may explain why patients with the most unfavorable prognosis exhibit the fastest increase in CCS. In other words, the patients with the highest risk succumb to the disease in the initial years, which leaves a healthier population of patients over time. Therefore, CS estimates may provide a more accurate and more optimistic prognostic prediction, particularly for patients who are initially predicted to have a poor prognosis.

Although the CCS3 for the four strategies increased steadily, no CCS3 rates reached $100 \%$, which is different from certain types of cancer, including thyroid and skin cancers (26). This result indicates that certain patients continued to succumb to cancer during follow up. However, as the mortality risk decreased with time elapsing, the CCS increased and reached a relatively higher survival rate, which is defined as the 'threshold value'. The present results suggested that patients with lobectomy reached a threshold value earlier compared with patients treated with other strategies. For example, CCS3 estimates for patients with lobectomy exceeded a threshold of $85 \% 1$ year after surgery, however, the CCS3 for patients with sublobar resection only reached $85 \% 4$ years after surgery. These results suggest that the follow-up period for stage I patients with lobectomy could possibly be shorter compared with patients who underwent sublobar resection. Therefore, dynamic CCS estimates may assist with the development of optimal surveillance strategies, particularly during the process of designing and reporting clinical trials.
According to the results of a Lung Cancer Study Group trial $(27,28)$, lobectomy has been the preferred option for the resection of early-stage NSCLC for two decades. Since lobectomy may impair lung function more compared with sublobar resection, it can be debated whether anatomic segmentectomy is an appropriate surgical strategy for small, peripheral tumors (29). Two randomized controlled trials are currently in progress, which are aiming compare perioperative and oncologic outcomes of patients receiving sublobar resection or lobectomy $(30,31)$. However, primary analysis of the overall survival endpoint is planned for 2020. Therefore, which surgical procedure is the most beneficial to offer the highest survival rate and safety remains unknown.

In the present study, lobectomy had the highest CCS3 and ACS rates among the four different treatment strategies for all time points, and it was closely followed by sublobar resection. This result suggests that lobectomy may be the best choice for early stage NSCLC, which is supported by previous studies $(10,32,33)$. To adjust the effects of demographic and pathological characteristics on prognosis, PSM was performed between lobectomy and sublobar resection, and no significant differences in covariables were identified following match. The survival outcomes were similar with those revealed prior to matching, which indicated that lobectomy was superior to sublobar resection in the cohort of cases with similar conditions. Patient selection with improved physical conditions, sufficient nodes dissection and improved operative technology may have resulted in improved survival outcomes following lobectomy. However, as certain studies have reported that the survival outcomes of lobectomy and sublobar resection are similar, the significant difference of survival outcomes between lobectomy and sublobar resection in the present study may have resulted from the lack of subdividing the location and size of tumor in the sublobar resection group $(34,35)$.

Referring to the non-surgical group, the ACS and CCS3 rates were markedly lower compared with the surgical group. The CCS3 of the observation group was lower compared with that of radiation group. In addition, the increase in the CCS3 in the observation group was faster compared with that of the radiation group regardless of whether the comparison was performed prior to or following matching, which demonstrates that observation leads to a poorer prognosis compared with radiation; however, as time progresses the CCS of patients treated by observation may be similar to that of patients treated by radiation.

The current study had numerous limitations that require attention. Firstly, the analysis was a retrospective study and some bias might occur (36). Second, confounders, including pulmonary function, consolidation tumor ratio and physical status were not available for adjustment in the study. Third, the current study lacked data regarding stereotactic body radiation therapy. Fourth, the present study only presented the calculating method of CS and took CCS3 as an example, while the CCS was not presented for patients who will survive for an extra 1 or 2 years, as was performed in a study by Fukui et al (37), which could provide more specific information for patients. However, based on the calculating method introduced, this information is easy to obtain. Fifth, other therapeutic effect assessment indexes, including recurrence-free CS and progression-free CS, were not investigated in the current study. Sixth, 
the follow-up data obtained from SEER used in the present study was cut-off in 2014; therefore, recent cases were not included. Finally, despite exploiting the statistical adjustments made by PSM, it may still be difficult to fully control potential confounding by indication in population-based analyses (38). Therefore, the findings should be further verified by prospective studies.

In conclusion, $\mathrm{CS}$ estimates may provide a more accurate and optimistic survival prediction, and may also assist with the generation of treatment decisions and surveillance strategies. Furthermore, the current analysis provided evidence that supports lobectomy as the optimal treatment strategy for I stage NSCLC treatment compared with sublobar resection.

\section{Acknowledgements}

Not applicable.

\section{Funding}

Not applicable.

\section{Availability of data and materials}

The datasets generated and/or analyzed during the current study are available from the SEER database, (https://seer. cancer.gov/).

\section{Authors' contributions}

YL conceived the study, performed the experiments, completed the analysis, drafted the manuscript, generated the figures and critically revised the manuscript. XF performed the experiments, completed the analysis, generated the figures and critically revised the manuscript. YB performed the experiments, supervised the project, generated the figures and critically revised the manuscript. DH conceived the study, performed the experiments, completed the analysis and critically revised the manuscript. CY conceived the study, drafted the manuscript, critically revised the manuscript, gave final approval of the version to be published, and supervised the project.

\section{Ethics approval and consent to participate}

Not applicable.

\section{Patient consent for publication}

Not applicable.

\section{Competing interests}

The authors declare that they have no competing interests.

\section{References}

1. Owonikoko TK, Ragin CC, Belani CP, Oton AB, Gooding WE, Taioli E and Ramalingam SS: Lung cancer in elderly patients: An analysis of the surveillance, epidemiology, and end results database. J Clin Oncol 25: 5570-5577, 2007.
2. Howington JA, Blum MG, Chang AC, Balekian AA and Murthy SC: Treatment of stage I and II non-small cell lung cancer: Diagnosis and management of lung cancer, 3rd ed: American College of Chest Physicians evidence-based clinical practice guidelines. Chest 143 (Suppl 5): e278S-e313S, 2013.

3. Dikken JL, Baser RE, Gonen M, Kattan MW, Shah MA, Verheij M, va de Velde CJ, Brennan MF and Coit DG: Conditional probability of survival nomogram for 1-, 2-, and 3-year survivors after an R0 resection for gastric cancer. Ann Surg Oncol 20: 1623-1630, 2013.

4. Henson DE and Ries LA: On the estimation of survival. Semin Surg Oncol 10: 2-6, 1994

5. Wang SJ, Fuller CD and Thomas CR Jr: Ethnic disparities in conditional survival of patients with non-small cell lung cancer. J Thorac Oncol 2: 180-190, 2007.

6. Skuladottir $\mathrm{H}$ and Olsen JH: Conditional survival of patients with the four major histologic subgroups of lung cancer in Denmark. J Clin Oncol 21: 3035-3040, 2003.

7. Merrill RM, Henson DE and Barnes M: Conditional survival among patients with carcinoma of the lung. Chest 116: 697-703, 1999.

8. Chen F, Cole P and Bina WF: Time trend and geographic patterns of lung adenocarcinoma in the United States, 1973-2002. Cancer Epidemiol Biomarkers Prev 16: 2724-2729, 2007.

9. Kim W, Lee HY, Jung SH, Woo MA, Kim HK, Choi YS, Kim J, Zo JI, Shim YM, Han J, et al: Dynamic prognostication using conditional survival analysis for patients with operable lung adenocarcinoma. Oncotarget 8: 32201-32211, 2017.

10. Shirvani SM, Jiang J, Chang JY, Welsh JW, Gomez DR, Swisher S, Buchholz TA and Smith BD: Comparative effectiveness of 5 treatment strategies for early-stage non-small cell lung cancer in the elderly. Int J Radiat Oncol Biol Phys 84: 1060-1070, 2012.

11. National Cancer Institue: Surveillance, Epidemiology, and End Results (SEER) Program. http://seer.cancer. gov. Accessed April, 2017.

12. Parzen JS, Bates JE, Milano MT and Dhakal S: Survival after subsequent non-Hodgkin's lymphoma and non-small cell lung cancer in patients with malignant thymoma. J Thorac Dis. 8: 3605-3613, 2016

13. Fitz A, Percy C, Jack A, Shanmugaratnam K, Sobin L, Max Parkin D and Whelan S (eds): ICD-O-3: International classification of Diseases for Oncology. 3rd edition. World Health Organization, Geneva, 2000.

14. Detterbeck FC, Boffa DJ, Kim AW and Tanoue LT: The eighth edition lung cancer stage classification. Chest 151: 193-203, 2017.

15. Austin PC: Statistical criteria for selecting the optimal number of untreated subjects matched to each treated subject when using many-to-one matching on the propensity score. Am J Epidemiol 172: 1092-1097, 2010.

16. Merrill RM, Henson DE and Ries LA: Conditional survival estimates in 34,963 patients with invasive carcinoma of the colon. Dis Colon Rectum 41: 1097-1106, 1998.

17. Henson DE, Ries LA and Carriaga MT: Conditional survival of 56,268 patients with breast cancer. Cancer 76: 237-242, 1995.

18. Nathan H, de Jong MC, Pulitano C, Ribero D, Strub J, Mentha G, Gigot JF, Schulick RD, Choti MA, Aldrighetti L, et al: Conditional survival after surgical resection of colorectal liver metastasis: An international multi-institutional analysis of 949 patients. J Am Coll Surg 210: 755-764, 2010.

19. Sun M, Trinh QD and Karakiewicz PI: Conditional survival of patients with metastatic renal-cell carcinoma. Lancet Oncol 13: e462, 2012.

20. Wang SJ,Emery R, Fuller CD, Kim JS, Sittig DF and Thomas CR: Conditional survival in gastric cancer: A SEER database analysis. Gastric Cancer 10: 153-158, 2007.

21. Mayo SC, Nathan H, Cameron JL, Olino K, Edil BH, Herman JM, Hirose K, Schulick RD, Choti MA, Wolfgang CL and Pawlik TM: Conditional survival in patients with pancreatic ductal adenocarcinoma resected with curative intent. Cancer 118: 2674-2681, 2012.

22. Kim Y, Ejaz A, Spolverato G, Squires MH, Poultsides G, Fields RC, Bloomston M, Weber SM, Votanopoulos K, Acher AW, et al: Conditional survival after surgical resection of gastric cancer: A multi-institutional analysis of the us gastric cancer collaborative. Ann Surg Onco 22: 557-564, 2015.

23. Kim Y, Margonis GA, Prescott JD, Tran TB, Postlewait LM, Maithel SK, Wang TS, Glenn JA, Hatzaras I, Shenoy R, et al: Curative Surgical Resection of Adrenocortical Carcinoma: Determining long-term outcome based on conditional disease-free probability. Ann Surg 265: 197-204, 2017. 
24. Lee JW, Ali B, Yoo HM, Park CH and Song KY: Conditional survival analysis in Korean patients with gastric cancer undergoing curative gastrectomy. BMC Cancer 15: 1005, 2015.

25. Merrill RM and Hunter BD: Conditional survival among cancer patients in the United States. Oncologist 15: 873-882, 2010.

26. Ito Y, Miyashiro I, Ito H, Hosono S, Chihara D, Nakata-Yamada K, Nakayama M, Matsuzaka M, Hattori M, Sugiyama H, et al: Long-term survival and conditional survival of cancer patients in Japan using population-based cancer registry data. Cancer Sci 105: 1480-1486, 2014.

27. Ginsberg RJ and Rubinstein LV: Randomized trial of lobectomy versus limited resection for T1 N0 non-small cell lung cancer. Lung Cancer Study Group. Ann Thorac Surg 60: 622-613, 1995.

28. Martin JT, Durbin EB, Chen L, Gal T, Mahan A, Ferraris V and Zwischenberger J: Nodal upstaging during lung cancer resection is associated with surgical approach. Ann Thorac Surg 101: $238-245,2016$.

29. Villamizar N and Swanson SJ: Lobectomy vs. Segmentectomy for NSCLC (T<2 cm). Ann Cardiothorac Surg 3: 160-166, 2014.

30. Kohman LJ, Gu L, Altorki N, Scalzetti E, Veit LJ, Wallen JM and Wang X: Biopsy first: Lessons learned from cancer and leukemia Group B (CALGB) 140503. J Thorac Cardiovasc Sury 153: 1592-1597, 2017.

31. Suzuki K, Saji SH, Aokage K, Watnabe SI, Okada M, Mizusawa J, Nakajima R, Tsuboi M, Nakamura S, Nakamura K et al: Comparison of morbidity of pulmonary segmentectomy and lobectomy: Safety results of a randomized trial. J Thorac Cardiovasc Surg: Apr 9, 2019 (Epub ahead of print). doi: 10.1016/j.jtcvs.2019.03.090.

32. Dai C, Shen J, Ren Y, Zhong S, Zheng H, He J, Xie D, Fei K, Liang W, Jiang G, et al: Choice of surgical procedure for patients with non-small-cell lung cancer $<=1 \mathrm{~cm}$ or $>1$ to $2 \mathrm{~cm}$ among lobectomy, segmentectomy, and wedge resection: A population-based study. J Clin Oncol 34: 3175-3182, 2016.
33. Whitson BA, Groth SS, Andrade RS, Maddaus MA, Habermann EB and D'Cunha J: Survival after lobectomy versus segmentectomy for stage I non-small cell lung cancer: A population-based analysis. Ann Thorac Surg 92: 1943-1950, 2011.

34. Cao J, Yuan P, Wang Y, Xu J, Yuan X, Wang Z, Lv W and Hu J: Survival rates after lobectomy, segmentectomy and wedge resection for the non-small cell lung cancer. Ann Thorac Surg 105: $1483-1491,2018$

35. Mery CM, Pappas AN, Bueno R, Colson YL, Linden P, Sugarbaker DJ and Jaklitsch MT: Similar long-term survival of elderly patients with non-small cell lung cancer treated with lobectomy or wedge resection within the surveillance, epidemiology, and end results database. Chest 128: 237-245, 2005.

36. Noone AM, Lund JL, Mariotto A, Cronin K, McNeel T, Deapen D and Warren JL: Comparison of SEER treatment data with medicare claims. Med Care 54: e55-e64, 2016.

37. Fukui T, Okasaka T, Kawaguchi K, Fukumoto K, Nakamura S, Hakiri S, Ozeki N and Yokoi K: Conditional survival after surgical intervention in patients with non-small cell lung cancer. Ann Thorac Surg 101: 1877-1882, 2016.

38. Bosco JL, Silliman RA, Thwin SS, Geiger AM, Buist DS, Prout MN, Yood MU, Haque R, Wei F and Lash TL: A most stubborn bias: No adjustment method fully resolves confounding by indication in observational studies. J Clin Epidemiol 63: 64-74, 2010.

(7) $\Theta$ This work is licensed under a Creative Common Attribution-NonCommercial-NoDerivatives 4.0 International (CC BY-NC-ND 4.0) License. 